\title{
Temporal Passage and Temporal Parts
}

\author{
L. NATHAN OAKLANDER \\ The University of Michigan-Flint
}

There are two perennial philosophical issues that have recently received considerable attention. The first concerns identity through time, and the second concerns temporal becoming. ${ }^{1}$ The purpose of this paper is to explore one important connection between these two issues. More specifically, I shall attempt to demonstrate that if one accepts the doctrine of four dimensional objects and temporal parts, then the tensed or A-theory of time cannot adequately explain the sense in which individual things, either persons or non-persons, are moving toward the future, or the sense in which the future is moving toward individual things. If true this would, in effect, render the tensed theory incompatible with the doctrine of temporal parts. Thus, it is a thesis worth considering and a useful place to begin a discussion of it is with an explication of (one version of) the tensed theory of time.

One of the most familiar features of our experience is the passage of time. Events which are once in the future become present and then recede into the more and more distant past as time passes. Not only events, but individual things such as sticks, stones and persons are presumed to be continually moving through time toward their eventual destruction or death. How is such temporal becoming, passage or change to be understood? According to the most prevalent version of the tensed or A-theory of time, temporal passage is to be understood literally; as ascribing to things and events the successive gain and loss of the metaphysically monadic temporal properties of pastness, presentness and futurity. Given this version of the tensed theory and the view that individual things are wholes composed of temporal parts, can any sense be given to the claim that individual things move through time from one moment to another? I do not think so, but before arguing the point we must clarify the doctrine of temporal parts.

Pre-analytically ordinary objects, including persons, are continuants; they persist (or exist) at more than one (or through) time. The philosophical issue concerns the analysis of that truth. What is a continuant and how does a continuant persist through time? The doctrine of four dimensional objects which incorporates the notion of temporal parts is one answer that has found favor 
among many contemporary philosophers. To see what is involved in that view, consider a spot, call it A, draw a line through the middle and color one part, call it ' $a_{1}$ ', green and the other part, call it ' $a_{2}$ ', red. Then we can say that a spot A which exists in part at $a_{1}$ is the same as the spot $A$ which exists in part at $a_{2}$, that it is one and the same spot that is red and green even though $a_{1}$ is not the same as $a_{2}$. On the temporal parts view, individual things are extended through time as they are extended through space: they persist by having different (and suitably related) temporal parts at different times. Accordingly, when someone says ' $\mathrm{P}$ is thinking of Descartes at $t_{1}$ ' he or she is referring to the entire extended whole and ascribing to it the property of having a $t_{1}$-part that is thinking of Descartes. As van Inwagen has recently put it,

this sentence ['Descartes was hungry at $t_{1}$ '] is exactly analogous to 'Water Street is narrow at the town line': in saying that you refer to the whole of Water Street and ascribe to it the property of having a narrow town-line-part. What occupies $R_{1}$ [a spatiotemporal slice of a four dimensional object] is not what anyone, ever, even at $t_{1}$ refers to as 'Descartes'; it is rather, a proper, temporal part of the single referent that Descartes always has (1990:247).

Thus, on the temporal parts approach the entire object is not wholly present at one or at many successive times. Rather, ordinary objects exist from one time to another in that different temporal parts of the entire, temporally extended, object exist at different times (cf. Heller [1990], Dau [1986]).

However, if an object $X$ is a whole composed of temporal parts, and if the tensed theory of time is true, then there are reasons to suppose that $\mathrm{X}$ cannot move through time. On the tensed theory the locution ' $X$ moves through time' implies that $\mathrm{X}$ exemplifies presentness (is present) at different times. In other words, as presentness moves from one time to another $\mathrm{X}$ allegedly moves along with it. Since, however, $X$ does not strictly speaking exist at different timesonly its temporal parts do (different temporal parts at different times)-it follows that $\mathrm{X}$ cannot exemplify presentness at different times, and therefore cannot move through time. To put the same point otherwise, though presentness can move from one temporal part of $\mathrm{X}$ to another, $\mathrm{X}$ itself cannot approach a future event by moving from one time to another since $X$ (as a temporal whole) does not literally exist at any time at which its temporal parts do. At best, each temporal part of $\mathrm{X}$ is successively becoming present, but it is difficult to understand how that would constitute $X$ moving in time.

Of course at any one time all the parts of $X$ have some transitory temporal property; each one is either past, present or future. But then the most we can say of $X$ is that it is partly past, partly present and partly future. We cannot say of $X$ that it is present simpliciter, but that is what we must be able to say for it to be true that ' $\mathrm{X}$ moves in time.'

The point can be made most clearly by comparing the temporal case with the spatial case. A spatial whole which is part green and part red is, strictly speaking, neither green nor red only partly each. Analogously, a temporal whole that is part 
past, part present, and part future is, strictly speaking, neither past, present nor future, but only partly each.

At this point a defender of the compatibility of temporal passage and temporal parts may reject the analogy between space and time and claim that in the temporal case a whole may have the same temporal property that a part has even if other parts of that whole exemplify different temporal properties. Specifically, a defender may argue that a temporal whole $\mathrm{W}$ is present if one of the W's temporal parts is present on the grounds that its denial entails a contradiction. Thus, if $\mathrm{W}$ is past (future) when one of its temporal parts is present, then $\mathrm{W}$ is past (future) when its earliest (latest) temporal part is present which is absurd. ${ }^{2}$

The problem with the above argument is that it proves too much since analogous reasoning can be used to support the thesis that $\mathrm{W}$ is past (future) if one of its parts is past (future). For example, to suppose that $\mathrm{W}$ is present (future) if one of its temporal parts is past, entails the absurdity that $\mathrm{W}$ is present (future) when its latest temporal part is past. Thus, the only argument for the thesis that $\mathrm{W}$ is present if a temporal part of $\mathrm{W}$ is present proves at most that $\mathrm{W}$ is partly past, partly present, and partly future, but not that $\mathrm{W}$ is present simpliciter; not that $\mathrm{W}$ exemplifies presentness. ${ }^{3}$

Thus, it would appear, prima facie, that if a thing is a whole of temporal parts, it cannot exemplify presentness at any one time. However, if it cannot be present at any one time, then it cannot literally move from one moment to the next as presentness moves from one of its temporal parts to the next. I conclude, therefore, that the traditional tensed theory of time is incompatible with the doctrine of temporal parts.

Two other versions of the theory of time that take tense seriously need to be considered before our thesis concerning the incompatibility between the passage of time and the temporal parts account of individual things can be claimed to be complete. According to the first, adopted by Roderick Chisholm (1981) and Arthur Prior (1968), events do not don and doff transitory temporal A-properties because there are no such properties for events to acquire and shed. Nor do events exist tenselessly in the B-series network of temporal relations. Rather, on this view of temporal becoming only the present exists. The future is what will exist, but does not yet exist and the past is what did exist, but no longer exists. Interestingly, both Chisholm and Prior reject the temporal parts analysis of identity through time and it is easy to see why. If there is no sense in which the past and future parts of a whole exist now (or more accurately, if all the temporal parts of a whole do not at every moment exemplify some transitory temporal property), then the past and the future do not exist. But if only one part of a whole person exists (is present) then it is impossible to say that the whole person exists (is present).

To this it may be objected that a whole can exist even if only one part is present, for it is possible that a whole has only one part. Thus, on the PriorChisholm tensed theory, we could say when time $t_{1}$ is present, the whole $W$ is composed only of the part $p_{1}$ that is then present, and when the later time $t_{2}$ is present, $\mathrm{W}$ is composed of the part $\mathrm{p}_{2}$ that is then present. The same whole is 
composed of different parts at different times, and as the successive parts become present (come into existence) the whole moves from one moment to another.

At the outset we should note that even if this argument is valid, it would establish that an ordinary object's passage through time is compatible with the doctrine of temporal parts only if one rejects mereological essentialism, the view that a whole has its parts necessarily. ${ }^{4}$ But the argument is not valid. Admittedly, if a whole had only one part then it would be present if the part was present. However, to suppose that a whole has only one part creates a dilemma. The whole is either identical with that part or it is not. If the relation between a part and the whole of which it is a part is identity, then a change in a part would imply a change in the whole. In that case, the coming into existence of a new and different temporal part would not help explain the movement of one and the same object from one time to another. If, on the other hand, a whole with only one part is not identical with that part, then what is it (identical with)? I can think of two possibilities: (1) an aggregate of (different) temporal parts that successively come into existence, or (2) a continuant without temporal parts. On the second possibility a whole is not composed of one (or many) temporal parts since it has none, and so its existence is irrelevant to the question of whether or not the doctrine of temporal parts is compatible with the passage of time. Unfortunately, the first alternative is equally unattractive. For if a whole is something distinct from its presently existing part and is the aggregate of all its parts, then it does not exist at any one time and so cannot, in any literal sense, move from one moment to the next as, according to the tensed theory, it must.

A final version of the tensed theory that I shall consider is a view recently put forth by David Zeilicovici (1989). The heart of his view is that the past and present do exist, but that the future does not exist. The passage of time consists in the replacement of one A-series (which contains past and present moments or events) with another A-series whose membership is increased. It would take us too far afield to go into the details of this view, which I have criticized elsewhere (Oaklander 1991b), but enough has been said to enable us to see why Zeilicovici's account of passage will not render it compatible with the doctrine of temporal parts. In fact, it seems to me that his view suffers from the defects of each of the preceding alternatives.

As on the traditional view of tense, at any given moment at which one temporal part is present there will exist other temporal parts that are past (except at the first moment of the "thing's" existence), and thus at any moment we can only say that $\mathrm{W}$ is partly past and partly present, but that does not enable us to give a sense of W's moving through time. Furthermore, since only the past and present parts of a whole exist, the point that we raised against Chisholm's view holds here too, namely, that a whole cannot exist at a moment if all the parts do not exist. Consider the spatial case again. If $A$ is the sum of $a, b$, and $c$, and only $a$ and $b$ exist, then A cannot exist. Similarly, if a temporal whole, $\mathrm{W}$, is a succession of temporal parts $\mathrm{p}_{1}, \mathrm{p}_{2}$, and $\mathrm{p}_{3}$, and only $\mathrm{p}_{1}$ and $\mathrm{p}_{2}$ exist, then $\mathrm{W}$ (in the sense of this whole) does not exist. And if $\mathrm{W}$ does not exist at any one time, then $\mathrm{W}$ cannot be 
said to literally move from one time to another. It would appear, then, that Zeilicovici's version of the tensed theory of time can no more render intelligible an individual's moving through time (given the doctrine of temporal parts) than can its predecessors. I conclude, therefore, that the tensed theory of temporal passage and the temporal parts analysis of continuants are incompatible. ${ }^{5}$

\section{Notes}

${ }^{1}$ For a sampling of recent literature on identity, including personal identity, see, Brennan (1988); Castañeda (1989a, b), Forbes (1987), Johnston (1987), Lowe (1988), Noonan (1989), Parfit (1984), Wiggins (1980) and Wilkes (1989). For recent work on temporal becoming see, Mellor (1981), Oaklander (1984, 1990, 1991a,b), Schlesinger (1980), Seddon (1987), Smart (1981), Smith (1987, 1992) and Zeilicovici (1989).

2This argument is found in Smith (1989; 4-5).

${ }^{3}$ Some may still claim, on the basis of different spatial analogy (for example, the whole ceiling is over the table when part of the ceiling is over it), that we can legitimately say that the whole is present if a part is present. However, the analogy fails because the two cases are dissimilar in a crucial respect: being over a table is a relation whereas being present is a non-relational property.

${ }^{4}$ In Castañeda (1989b) it is argued that mereological essentialism is incorrect about our ordinary objects, which are conceived as Aristotelian substances in a hierarchy of emergent individuals among lower materials.

${ }^{5}$ I have benefitted greatly from the written comments on earlier versions of this paper by HectorNeri Castañeda, Ronald C. Hoy, and Quentin Smith. I also wish to thank Charles E.M. Dunlop and Gregory Trianosky for stimulating conversations on the issues surrounding this paper. Research for this paper was partially funded by The University of Michigan-Flint.

\section{References}

Brennan, Andew

1988 Conditions of Identity (Oxford: University Press).

Castañeda, Hector-N.

1989a "Reflexivity of Self-Consciousness: Sameness/Identity, Data for Artificial Intelligence," Philosophical Topics, 17:27-58.

1989b “Objects, Identity, and Sameness," Topoi Supplement 4, The Object and its Identity: 31-64.

Chisholm, Roderick M.

1981 The First Person (Minneapolis: University of Minnesota Press).

Dau, Pablo

1986 "Part-Time Objects," in P.A. French, T.E. Uehling, Jr. and H.K. Wettstein eds., Midwest Studies in Philosophy XI: 323-334 (Minnesota: University Press).

Forbes, Graeme

1987 "Is There a Problem About Persistence," The Aristotelian Society's Supplementary Volume LXI: 137-155.

Heller, Mark

1990 The Ontology of Physical Objects (Cambridge: University Press).

Johnston, Mark

1987 "Is There a Problem About Persistence," The Aristotelian Society's Supplementary Volume LXI: 107-135. 
Lowe, E.J.

1988 "Substance, Identity and Time," The Aristotelian Society's Supplementary Volume LXII 61-78.

Mellor, D.H.

1981 Real Time (Oxford: Cambridge University Press).

Noonan, Harold

1989 Personal Identity (New York: Routledge).

Oaklander, L. Nathan

1984 Temporal Relations and Temporal Becoming (Lanham, MD: Univ. Press of America).

1990 "The New Tenseless Theory of Time: A Reply to Smith, "Philosophical Studies 55: $17-22$.

1991a "A Defence of the New Tenseless Theory of Time," The Philosophical Quarterly 41: 27-38

$1991 b$ "Zeilicovici on Temporal Becoming," Philosophia.

Parfit, Derek

1984 Reasons and Persons (Oxford: University Press).

Prior, Arthur N.

1968 Time and Tense (Oxford: University Press).

Schlesinger, George

1980 Aspects of Time (Indianapolis: Hackett Publishing Company).

Seddon, Keith

1987 Time: A Philosophical Treatment (London: Croon Helm).

Smart, J.J.C.

1980 "Time and Becoming," in Peter van Inwagen ed. Time and Cause (Dordrecht: D. Reidel): 3-15.

$\rightarrow$ Smith, Quentin

1987 "Problems with the New Tenseless Theory of Time," Philosophical Studies 52: 371-392.

1989 "Personal Identity and Time," unpublished manuscript read at the Central States Philosophical Association Meetings in Iowa City, Iowa.

1991 Language and Time: A Defense of Presentism.

$\rightarrow$ van Inwagen, Peter

1990 "Four dimensional Objects," NOUS, 24: 245-255.

Wiggins, David

1980 Sameness and Substance (Oxford: Basil Blackwell Pub. Ltd.).

Wilkes, Kathleen V.

1988 Real People (Oxford: Oxford University Préss).

$\rightarrow$ Zeilicovici, David

1989 “Temporal Becoming Minus the Moving Now," NOUS, 23: 505-524. 